\title{
Topical rebamipide improves lid wiper epitheliopathy
}

\author{
This article was published in the following Dove Press journal: \\ Clinical Ophthalmology \\ 30 October 2013 \\ Number of times this article has been viewed
}

\author{
Hirotaka Itakura ${ }^{1,2}$ \\ Tomoyuki Kashima ${ }^{2}$ \\ Mariko Itakura' \\ Hideo Akiyama ${ }^{2}$ \\ Shoji Kishi ${ }^{2}$ \\ 'Department of Ophthalmology, \\ Maebashi Red Cross Hospital, \\ ${ }^{2}$ Department of Ophthalmology, \\ Gunma University, School of Medicine, \\ Maebashi, Japan
}

\begin{abstract}
Administration of topical rebamipide increases the mucin level of tear film and improves the ocular surface in short break-up time type of dry eye. Lid wiper epitheliopathy (LWE) is a disorder of the marginal conjunctiva of the upper eyelid with dry eye symptoms. LWE may be related to mechanical forces during blinking resulting in inflammation of the ocular surface. Rebamipide also has various anti-inflammatory effects. In this report, we tried treatment with topical rebamipide for two cases of LWE. One case had been treated with sodium hyaluronate ophthalmic solution and diquafosol sodium eye drops by other doctors for several weeks. The other case was not previously treated. In both cases, fluorescein staining of the cornea and lid margin was remarkably improved, ocular symptoms decreased, and tear film break-up times increased with rebamipide eye drops four times daily for $2-3$ weeks. Topical rebamipide was effective for corneal and conjunctival disorders in LWE. This drug may provide a novel approach to the treatment of LWE.
\end{abstract}

Keywords: corneal erosion, dry eye, lid wiper, Mucosta ${ }^{\circledR}$, mucin, rebamipide

\section{Introduction}

Administration of topical rebamipide increases secretion of mucins from goblet cells and improves the ocular surface in short break-up time type of dry eye. ${ }^{1,2}$ The human eyelid margin looks histologically to be an important structure for the maintenance of tear film. ${ }^{3}$ In particular, the epithelium of the crest of the inner lid border is composed of larger cuboidal and less dense typical conjunctival cells together with interspersed goblet cells, which appears to be a suitable structure to spread the tear film. ${ }^{4}$ Lid wiper epitheliopathy (LWE) is an alteration of the portion of the marginal conjunctival epithelium of the upper eyelid (the lid wiper) that wipes the ocular surface during blinking and induces dry eye symptoms. ${ }^{5-7}$ LWE has been reported to occur both with and without contact lens wear. ${ }^{6,7}$ LWE may be related to mechanical forces during blinking, resulting in inflammation of the ocular surface. ${ }^{8}$

The tear film is composed of a mixture of lipid, lacrimal fluid, and mucins. ${ }^{9}$ On the ocular surface, there are two types of mucins. One is a secreted type supplied from conjunctival goblet cells, and the other is a membrane-associated type on the surface of the cornea and conjunctival epithelium. ${ }^{10}$ Administration of rebamipide can increase corneal and conjunctival mucins and ameliorate injury of the ocular surface in vivo. ${ }^{11,12}$

Because rebamipide increases mucin production in cultured conjunctival goblet cells $s^{13,14}$ and corneal epithelial cells, rebamipide may increase the secretion of both membrane-associated and secreted-type mucins. ${ }^{15}$ Previously, an oral rebamipide
Correspondence: Hirotaka Itakura

Maebashi Red Cross Hospital,

3-21-36 Asahi-cho, Maebashi,

Gunma 37I-00 I4, Japan

Tel +81272244585

Fax +81272433380

Email itakura@gunma-u.ac.jp submit your manuscript $\mid$ www.dovepress.com

Dovepress

http://dx.doi.org// 0.2147/OPTH.S545II 
formulation has been used as an antiulcer agent for gastric ulcers and gastritis. ${ }^{16}$ Rebamipide increases gastric endogenous prostaglandin E2 and I 2 to promote gastric epithelial mucin, ${ }^{17,18}$ with free radical scavenging activity ${ }^{19,20}$ and an anti-inflammatory effect. ${ }^{21,22}$

Recently, the clinical effects of rebamipide eye drops (Mucosta ${ }^{\circledR}$ ophthalmic suspension UD2\%; Otsuka Pharmaceutical Co, Ltd, Tokyo, Japan) for various types of dry eye were reported., ${ }^{1,23,24}$ Rebamipide eye drops for dry eye are also being developed for approval in the US. In this case report, we tried treatment with topical rebamipide for two cases of LWE according to our previous study. ${ }^{24}$

\section{Case report I}

The patient was a 77-year-old female, diagnosed with dry eye at another clinic and treated with sodium hyaluronate ophthalmic solution and diquafosol sodium eye drops for several weeks. She has never worn contact lenses on a regular basis. Because of lack of improvement in her subjective symptoms, she visited Maebashi Red Cross Hospital. Her ocular symptoms were dryness and blurred vision in the right eye. Slit-lamp microscopy with fluorescein staining showed diffuse corneal erosion in the superior cornea and lid wiper staining with hyperemia of the palpebral conjunctiva in the right eye (Figure 1, upper panels). With a diagnosis of LWE, rebamipide eye drops four times daily were prescribed and her other eye drops were discontinued. Fluorescein staining of the cornea and lid margin was remarkably improved (Figure 1, lower panels) and subjective symptoms were reduced in 2 weeks from the start of rebamipide eye drops. Tear film break-up time (TBUT), Schirmer's 1 test, and decimal visual acuity were examined before and 2 weeks after administration of rebamipide (Table 1). For TBUT, corneal staining with fluorescein solution was examined under standard illumination using a slit-lamp microscope with a cobalt blue filter. TBUT was measured three times using a stopwatch as the time from normal blinking to the first appearance of a dry spot in the tear film. Schirmer's 1 test was performed to measure tear volume.

\section{Case report 2}

The patient was a 71-year-old female on no medication during follow-up after cataract surgery 3 years earlier. She complained of foreign body sensation and blurred vision in the left eye and visited our hospital. Slit-lamp microscopy with fluorescein staining showed band-shaped corneal erosion in the central cornea and lid wiper staining with hyperemia of the palpebral conjunctiva in the right eye (Figure 2, upper panels). We diagnosed this as LWE and administered rebamipide eye drops four times daily to her right eye. Fluorescein staining of the cornea and lid margin was remarkably improved (Figure 2, lower panels) and subjective symptoms resolved in 3 weeks. TBUT, Schirmer's 1 test, and decimal visual acuity were examined before and 3 weeks after administration of rebamipide in the same way as in case 1 (Table 1).
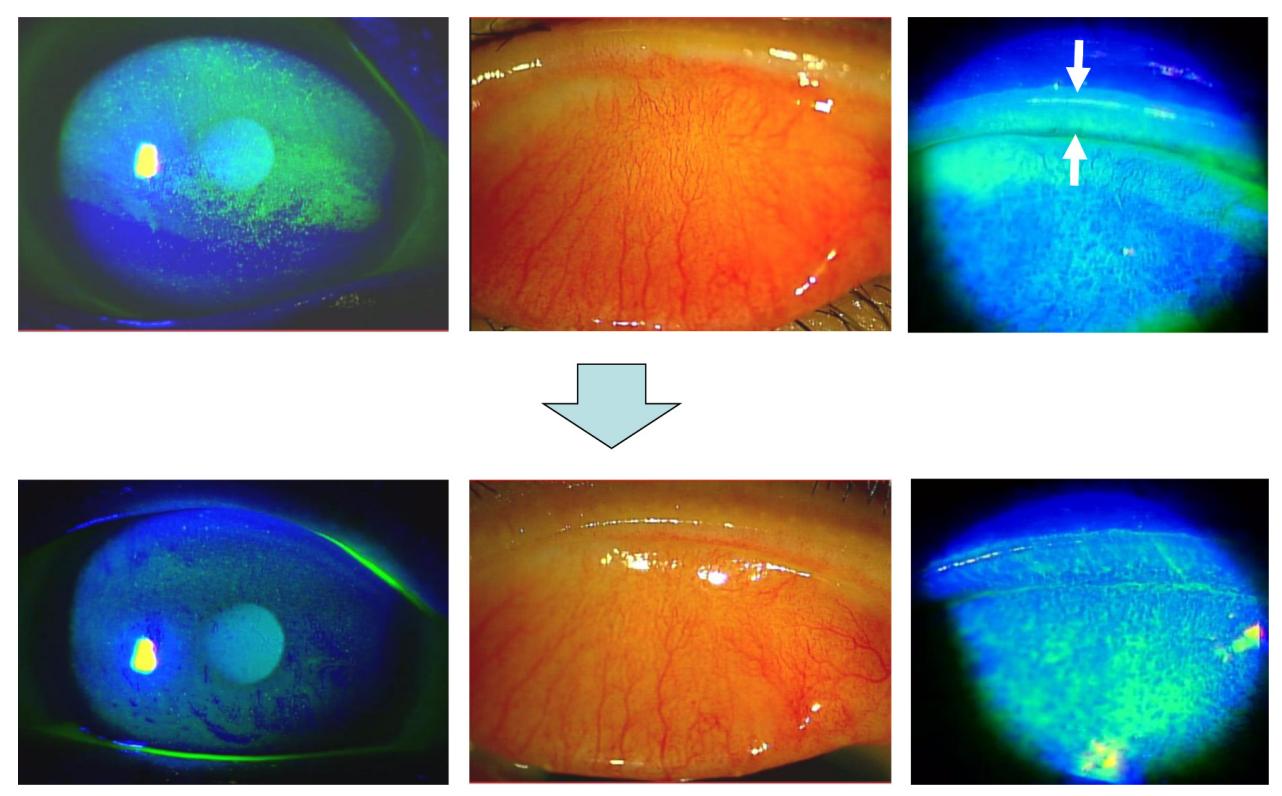

Figure I A 77-year-old female. Slit lamp microscopy with fluorescein staining showed diffuse corneal erosion in the superior cornea (upper left) and lid wiper staining (upper right, white arrows) with hyperemia of palpebral conjunctiva in the right eye (upper middle). Fluorescein staining of the cornea and lid margin was improved in 2 weeks after administration of topical rebamipide eye drops (lower images). 
Table I Clinical data

\begin{tabular}{lllll}
\hline & Case I & \multicolumn{3}{c}{ Case 2 } \\
\cline { 2 - 5 } & Before & $\begin{array}{l}\text { After } \\
\text { 2 weeks }\end{array}$ & Before & After \\
& & & 3 weeks \\
\hline Tear film BUT (seconds) & 2.7 & 4.5 & 3.8 & 6.2 \\
Schirmer's I test (mm) & 5 & 6 & 11 & 10 \\
Decimal VA & 0.8 & 1.2 & 0.7 & 1.0 \\
\hline
\end{tabular}

Abbreviations: BUT, break-up time; VA, visual acuity.

\section{Discussion}

Here we report the effect of rebamipide eye drops for LWE in two patients. Two to three weeks after administration of rebamipide eye drops, corneal erosions disappeared, injection and fluorescein staining of the lid wiper decreased, TBUT was extended, and symptoms were improved in both cases.

LWE is a disease concept that was reported for the first time in 2002 by Korb et al. ${ }^{6}$ LWE was detected by ocular staining with an alteration of the marginal conjunctival epithelium of the upper eyelid that wipes the ocular surface during blinking. ${ }^{6,7}$ Korb et al detected LWE by ocular staining with fluorescein and lissamine green..$^{5-7}$ Because fluorescein staining is stronger than lissamine green, they graded LWE from zero to grade 3 for the horizontal length involved and the average sagittal height involved using the findings of fluorescein staining. ${ }^{5}$ According to their grading, case 1 was grade 2 LWE (horizontal length 5-9 $\mathrm{mm}$ and sagittal height 50\%-75\%) and case 2 was grade 3 LWE (horizontal length $>10 \mathrm{~mm}$ and sagittal height $>75 \%$ ).
LWE may be related to mechanical forces during blinking resulting in inflammation of the ocular surface. ${ }^{8}$ Function within the normal structure of the eye lid is critical for wettability of the ocular surface to prevent evaporation of the normal tear film..$^{25}$ The wettability of the ocular surface and the properties of tear fluids are principal factors in precorneal tear film stability. ${ }^{26,27}$ In LWE, tear film stability may decrease as a result of friction between the eyelid and the ocular surface.

Membrane-associated mucins contribute to the wettability of the ocular surface. ${ }^{28}$ The epithelium of the lid wiper is composed of larger cuboidal cells and less dense squamous cells with interspersed goblet cells. ${ }^{3,4}$ In LWE, secretion of mucins from goblet cells of the lid wiper itself may decrease. Rebamipide increases mucin production from conjunctival goblet cells ${ }^{13,14}$ and corneal epithelial cells. ${ }^{15}$ We speculate that rebamipide increased tear stability via increased mucin secretion, which contributed to improving the corneal erosion due to LWE.

In case 1, although treatments with sodium hyaluronate ophthalmic solution and diquafosol sodium eye drops were performed before the first visit to our hospital, the patient's corneal disorders and complaints were not improved. Diquafosol sodium eye drops also increase secretion of mucins and improve tear film stability in short TBUT type of dry eye. ${ }^{29,30}$ In this case, the effect of diquafosol sodium eye drops was insufficient. Previous studies have demonstrated that rebamipide has various anti-inflammatory effects. ${ }^{19,22}$ Because LWE may be related to chronic inflammation as a
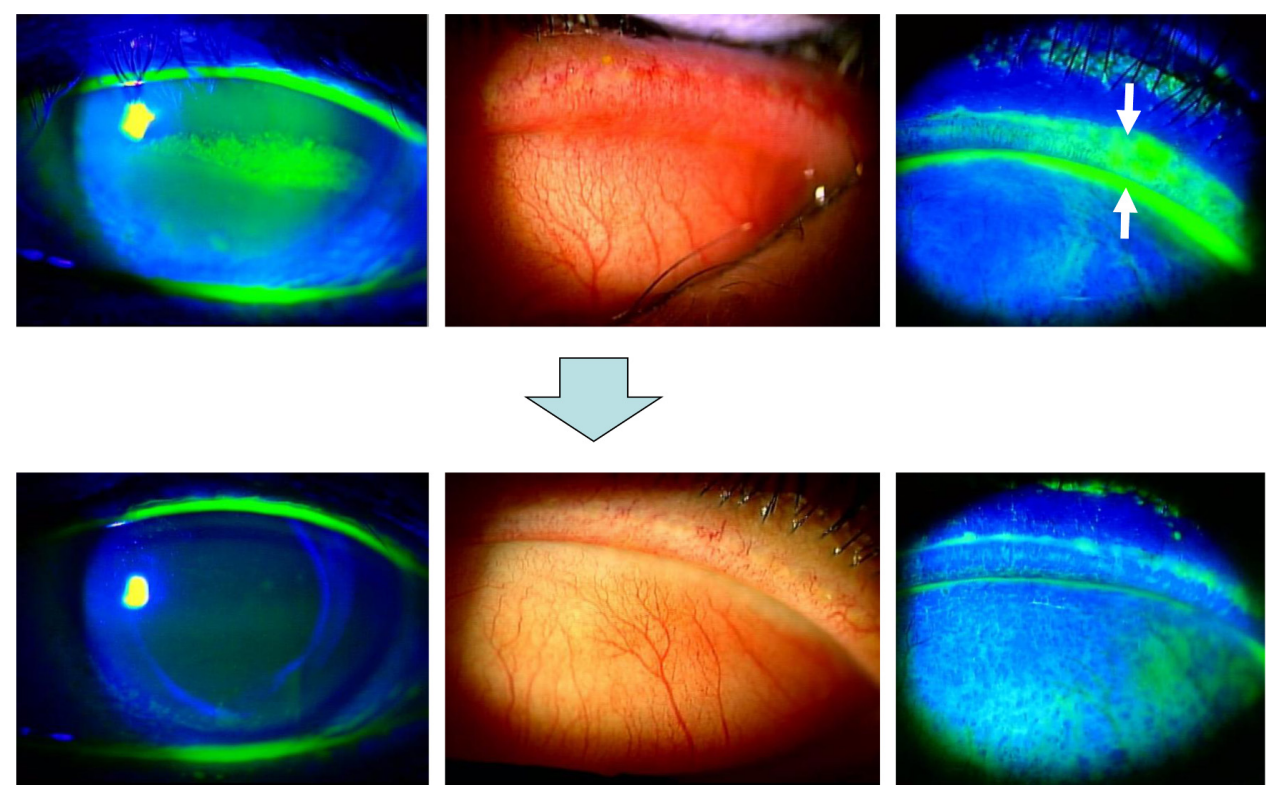

Figure 2 A 7I-year-old female. Slit lamp microscopy with fluorescein staining showed band-shaped corneal erosion in the central cornea (upper left)and lid wiper staining (upper right, white arrows) with hyperemia of palpebral conjunctiva in the left eye (upper middle). Fluorescein staining of the cornea and lid margin was improved in 3 weeks after administration of topical rebamipide eye drops (lower images). 
result of friction between the eyelid and the ocular surface, rebamipide may reduce this inflammation. Although sodium hyaluronate is known to suppress inflammation and diquafosol is known to downregulate inflammatory cytokine expression as well as stimulate tear and mucin secretion, the anti-inflammatory effect of rebamipide may be greater than that of sodium hyaluronate and diquafosol. Traditional anti-inflammatory agents may also be useful for LWE.

Rebamipide eye drops could be an alternative treatment for LWE refractory to existing treatments and may become a first choice for patients with LWE.

Although side effects of rebamipide eye drops, including bitter taste, eye irritation, eye pruritus, and blurred vision, have been reported, there were no side effects in our two cases. However, in this report, the number of patients was very small and there was no control group. Further investigations should be carried out in a larger number of cases with a control group.

LWE can be included in dry eye or meibomian gland dysfunction. Several methods have been used to treat LWE, including lubricants, anti-inflammatory agents, and treatments for meibomian gland dysfunction. The tear film is composed of a lipid layer overlying an aqueous layer that is a mixture of lacrimal fluid and mucins. ${ }^{9}$ Lipids secreted from the meibomian gland serve as the lipid layer. Blinking is related to meibomian gland function. ${ }^{31}$ Meibography can assess the relationship between morphologic changes and the eyelid and tear film parameters. ${ }^{32}$ Meibography may also be useful for examining meibomian gland function with LWE. Application of a low-dose lipid ointment may improve dry eye. ${ }^{33}$ As our previous report concerning the effect of rebamipide eye drops on corneal disorders in mild lagophthalmos, ${ }^{24}$ the combination of ointments, artificial tears, and rebamipide eye drops may be a more appropriate approach to treating LWE.

\section{Disclosure}

The authors have no financial interests related to this report. The authors report no other conflicts of interest in this work.

\section{References}

1. Kinoshita S, Awamura S, Oshiden K, Nakamichi N, Suzuki H, Yokoi N; Rebamipide Ophthalmic Suspension Phase II Study Group. Rebamipide (OPC-12759) in the treatment of dry eye: a randomized, double-masked, multicenter, placebo-controlled Phase II study. Ophthalmology. 2012;119(12):2471-2478.

2. Koh S, Inoue Y, Sugmimoto T, Maeda N, Nishida K. Effect of rebamipide ophthalmic suspension on optical quality in the short break-up time type of dry eye. Cornea. 2013;32(9):1219-1223.

3. Knop E, Knop N, Zhivov A, et al. The lid wiper and muco-cutaneous junction anatomy of the human eyelid margins: an in vivo confocal and histological study. J Anat. 2011;218(4):449-461.
4. Knop N, Korb DR, Blackie CA, Knop E. The lid wiper contains goblet cells and goblet cell crypts for ocular surface lubrication during the blink. Cornea. 2012;31(6):668-679.

5. Korb DR, Herman JP, Blackie CA, et al. Prevalence of lid wiper epitheliopathy in subjects with dry eye signs and symptoms. Cornea. 2010;29(4):377-383.

6. Korb DR, Herman JP, Greiner JV, et al. Lid wiper epitheliopathy and dry eye symptoms. Eye Contact Lens. 2005;31(1):2-8.

7. Korb DR, Greiner JV, Herman JP, et al. Lid-wiper epitheliopathy and dry-eye symptoms in contact lens wearers. CLAO J. 2002;28(4): 211-216.

8. Berry M, Pult H, Purslow C, Murphy PJ. Mucins and ocular signs in symptomatic and asymptomatic contact lens wear. Optom Vis Sci. 2008;85(10):E930-E938.

9. Gipson IK. The ocular surface: the challenge to enable and protect vision. The Friedenwald lecture. Invest Ophthalmol Vis Sci. 2007; 48(10):4390-4398.

10. Gipson IK. Distribution of mucins at the ocular surface. Exp Eye Res. 2004;78(3):379-388.

11. Urashima H, Okamoto T, Takeji Y, Shinohara H, Fujisawa S. Rebamipide increases the amount of mucin-like substances on the conjunctiva and cornea in the $\mathrm{N}$-acetylcysteine-treated in vivo model. Cornea. 2004;23(6):613-619.

12. Tanito M, Takanashi T, Kaidzu S, Yoshida Y, Ohira A. Cytoprotective effects of rebamipide and carteolol hydrochloride against ultraviolet B-induced corneal damage in mice. Invest Ophthalmol Vis Sci. 2003;44(7):2980-2985.

13. Rios JD, Shatos M, Urashima H, Tran H, Dartt DA. OPC12759 increases proliferation of cultured rat conjunctival goblet cells. Cornea. 2006;25(5):573-581.

14. Rios JD, Shatos MA, Urashima H, Dartt DA. Effect of OPC-12759 on EGF receptor activation, p44/p42 MAPK activity, and secretion in conjunctival goblet cells. Exp Eye Res. 2008;86(4):629-636.

15. Takeji Y, Urashima H, Aoki A, Shinohara H. Rebamipide increases the mucin-like glycoprotein production in corneal epithelial cells. J Ocul Pharmacol Ther. 2012;28(3):259-263.

16. Uchida M, Tabusa F, Komatsu M, Morita S, Kanbe T, Nakagawa K. Studies on 2(1H)-quinolinone derivatives as gastric antiulcer active agents. 2-(4-chlorobenzoylamino)-3-[2(1H)-quinolinon-4-yl]propionic acid and related compounds. Chem Pharm Bull (Tokyo). 1985;33(9):3775-3786.

17. Yamasaki K, Kanbe T, Chijiwa T, Ishiyama H, Morita S. Gastric mucosal protection by OPC-12759, a novel antiulcer compound, in the rat. Eur J Pharmacol. 1987;142(1):23-29.

18. Kleine A, Kluge S, Peskar BM. Stimulation of prostaglandin biosynthesis mediates gastroprotective effect of rebamipide in rats. Dig Dis Sci. 1993;38(8):1441-1449.

19. Yoshikawa T, Naito Y, Tanigawa T, Kondo M. Free radical scavenging activity of the novel anti-ulcer agent rebamipide studied by electron spin resonance. Arzneimittelforschung. 1993;43(3):363-366.

20. Naito Y, Yoshikawa T, Tanigawa T, et al. Hydroxyl radical scavenging by rebamipide and related compounds: electron paramagnetic resonance study. Free Radic Biol Med. 1995;18(1):117-123.

21. Arakawa T, Kobayashi K. Quality of ulcer healing - a new concept to rank healed peptic ulcers. Gastroenterol Jpn. 1993;28 Suppl 5: $158-162$.

22. Aihara M, Imagawa K, Funakoshi Y, Ohmoto Y, Kikuchi M. Effects of rebamipide on production of several cytokines by human peripheral blood mononuclear cells. Dig Dis Sci. 1998;43 Suppl 9: $160 \mathrm{~S}-166 \mathrm{~S}$.

23. Kashima T, Akiyama H, Miura F, Kishi S. Resolution of persistent corneal erosion after administration of topical rebamipide. Clin Ophthalmol. 2012;6:1403-1406.

24. Itakura M, Itakura H, Kashima T, Akiyama H, Kishi S. Topical rebamipide improves the ocular surface in mild lagophthalmos. Clin Ophthalmol. 2013;7:1333-1338.

25. Terry MA. Dry eye in the elderly. Drugs Aging. 2001;18(2):101-107. 
26. Holly FJ, Lemp MA. Wettability and wetting of corneal epithelium. Exp Eye Res. 1971;11(2):239-250.

27. Tiffany JM, Winter N, Bliss G. Tear film stability and tear surface tension. Curr Eye Res. 1989;8(5):507-515.

28. Gipson IK, Hori Y, Argüeso P. Character of ocular surface mucins and their alteration in dry eye disease. Ocul Surf. 2004;2(2):131-148.

29. Shimazaki-Den S, Iseda H, Dogru M, Shimazaki J. Effects of diquafosol sodium eye drops on tear film stability in short BUT type of dry eye. Cornea. 2013;32(8):1120-1125.

30. Takamura E, Tsubota K, Watanabe H, Ohashi Y; Diquafosol Ophthalmic Solution Phase 3 Study Group. A randomised, doublemasked comparison study of diquafosol versus sodium hyaluronate ophthalmic solutions in dry eye patients. Br J Ophthalmol. 2012;96(10): 1310-1315.
31. Korb DR, Baron DF, Herman JP, et al. Tear film lipid layer thickness as a function of blinking. Cornea. 1994;13(4):354-359.

32. Arita R, Itoh K, Maeda S, Maeda K, Tomidokoro A, Amano S. Efficacy of diagnostic criteria for the differential diagnosis between obstructive meibomian gland dysfunction and aqueous deficiency dry eye. Jpn $J$ Ophthalmol. 2010;54(5):387-391.

33. Goto E, Dogru M, Fukagawa K, et al. Successful tear lipid layer treatment for refractory dry eye in office workers by low-dose lipid application on the full-length eyelid margin. Am J Ophthalmol. 2006;142(2):264-270.
Clinical Ophthalmology

\section{Publish your work in this journal}

Clinical Ophthalmology is an international, peer-reviewed journal covering all subspecialties within ophthalmology. Key topics include: Optometry; Visual science; Pharmacology and drug therapy in eye diseases; Basic Sciences; Primary and Secondary eye care; Patien Safety and Quality of Care Improvements. This journal is indexed on

Submit your manuscript here: http://www.dovepress.com/clinical-ophthalmology-journal

\section{Dovepress}

PubMed Central and CAS, and is the official journal of The Society of Clinical Ophthalmology (SCO). The manuscript management system is completely online and includes a very quick and fair peer-review system, which is all easy to use. Visit http://www.dovepress.com/ testimonials.php to read real quotes from published authors. 